\title{
Long- and Short-Term Monitoring of a Dam in Response to Seasonal Changes and Ground Motion Loading: The Test Case of the Kurpsai Dam, Western Kyrgyz Republic
}

\author{
Marco Pilz, ${ }^{1}$ (D) Marius Paul Isken, ${ }^{1,2}$ Kevin Fleming, ${ }^{1}$ Sagynbek Orunbaev, ${ }^{3}$ and Bolot Moldobekov ${ }^{3}$
}

\begin{abstract}
An experimental multi-parameter structural monitoring system has been installed on the Kurpsai dam, western Kyrgyz Republic. This system consists of equipment for seismic and strain measurements for making longer- (days, weeks, months) and shorter- (minutes, hours) term observations, dealing with, for example seasonal (longer) effects or the response of the dam to ground motion from noise or seismic events. Fibre-optic strain sensors allow the seasonal and daily opening and closing of the spaces between the dam's segments to be tracked. For the seismic data, both amplitude (in terms of using differences in amplitudes in the Fourier spectra for mapping the modes of vibration of the dam) and their time-frequency distribution for a set of small to moderate seismic events are investigated and the corresponding phase variabilities (in terms of lagged coherency) are evaluated. Even for moderate levels of seismic-induced ground motion, some influence on the structural response can be detected, which then sees the dam quickly return to its original state. A seasonal component was identified in the strain measurements, while levels of noise arising from the operation of the dam's generators and associated water flow have been provisionally identified.
\end{abstract}

Keywords: Structural health monitoring, Dam engineering, Operational and environmental effects, Strong-motion, Strain, Elastic response, Kurpsai dam.

\section{Introduction}

The Kyrgyz Republic in Central Asia is an area of moderately high seismic hazard and risk. This is due to the ongoing collision between the Indian and Eurasian continental plates, resulting in the development of major mountain ranges, such as the Tian

1 Section 2.6 Seismic Hazard and Risk Dynamics, GFZ Potsdam, German Research Centre for Geosciences, Telegrafenberg, 14473 Potsdam, Germany. E-mail: pilz@gfz-potsdam.de

2 Institute of Geosciences, University of Potsdam, Am Neuen Palais 10, 14469 Potsdam, Germany.

3 Central Asian Institute of Applied Geosciences, Timur Frunze Rd.73/2, 720027 Bishkek, Kyrgyz Republic.
Shan and the Pamir (e.g., Ischuk et al., 2017; Thompson et al., 2002). As an indication of this, over the past 140 years, the Kyrgyz Republic and the surrounding region have experienced several strong earthquakes with magnitudes greater than $M 7$, for example, the 1887 Verniy (moment magnitude $\mathrm{Mw}=7.2)$, the 1889 Chilik $(\mathrm{Mw}=8.3)$, and the 1911 Kemin $(\mathrm{Mw}=7.7)$ events, while more recently there were the 1946 Chatkal $(\mathrm{Mw}=7.5)$ and the 1992 Suusamyr $(\mathrm{Mw}=7.2)$ earthquakes (Kalmetieva et al., 2009). Coupled with such seismic activity is the danger of landslides, especially relevant given the mountainous nature of the country (e.g., Havenith et al., 2015a, 2016; Nadim et al., 2006).

The presence of mountainous terrain and rivers leads to the potential of the country developing hydropower for domestic use and export. However, because of the seismic hazard that affects these areas, there is a need for monitoring techniques to identify ground shaking induced by seismic events (and dayto-day operations) to help oversee the structural health of existing and future hydropower generation facilities. By doing so, our understanding of the response of these structures to such events will help to develop schemes that will ensure their long-term structural integrity. Moreover, there is the fact that much of the infrastructure related to existing dams are ageing, with five of the seven largest dams in the Kyrgyz Republic being over 30 years old (International Hydropower Association, 2018). Significant temperature changes between the winter and summer seasons further impact upon these built structures, potentially negatively impacting upon their structural integrity.

In response to these concerns, the recently completed MI-DAM (Multi-parameter monitoring and 
risk assessment of hydropower dams in the Kyrgyz Republic) project set out to develop, install, and test a cost-effective and flexible multi-parameter monitoring system for such infrastructure (Petryna et al., 2019; Pilz et al., 2019). The test case was the Kurpsai hydropower station, located in the western part of the country on the Naryn River (Figs. 1 and 2), upon which several hydropower facilities are located (Havenith et al., 2015b; Kormev, 1981).

The investigation aimed to monitor the dam's structural behaviour using a multi-parameter scheme, considering two time scales: the longer-term measurement of static deformations over days, weeks, and months, arising from the opening and closing of the spaces between the dam's segments, largely due to seasonal temperature changes, and short-term monitoring over minutes and hours of the dam's response to earthquake-induced ground motion and different operational regimes. The multi-parameter measurements involve various techniques, namely absolute static displacements measured by GNSS receivers placed on top of each segment that makes
Figure 2

a The study area, showing its topography and the locations of the six hydropower dams on the Naryn River (red squares, with Kurpsai a red diamond), the ACROSS network seismic stations (blue triangles; Parolai et al., 2017), and recent major events. b The best-resolved faults in the study area (dark lines) and the seismic events (green circles $M \geq 3$, blue circles $M \geq 4$ ) that occurred between 01.08.2018 and 31.09.2019. The yellow stars (Table 2) are the examples used in the event and coherency analysis presented below

up the dam's structure, measurements by fibre-optic strain sensors, some of which were linked to temperature sensors (Petryna et al., 2019), and seismic instruments distributed on the dam's crest and either side of the dam on bedrock (Pilz et al., 2019). Such an instrumental arrangement allows the continuous recording of persistent natural and anthropogenic vibrations and ground motions that pass through the dam's structure, potentially permitting the dam's mechanical characteristics to be updated in real-time. The early detection of such changes may in turn serve as input for early warning systems and for the calibration of numerical models that describe the dam's

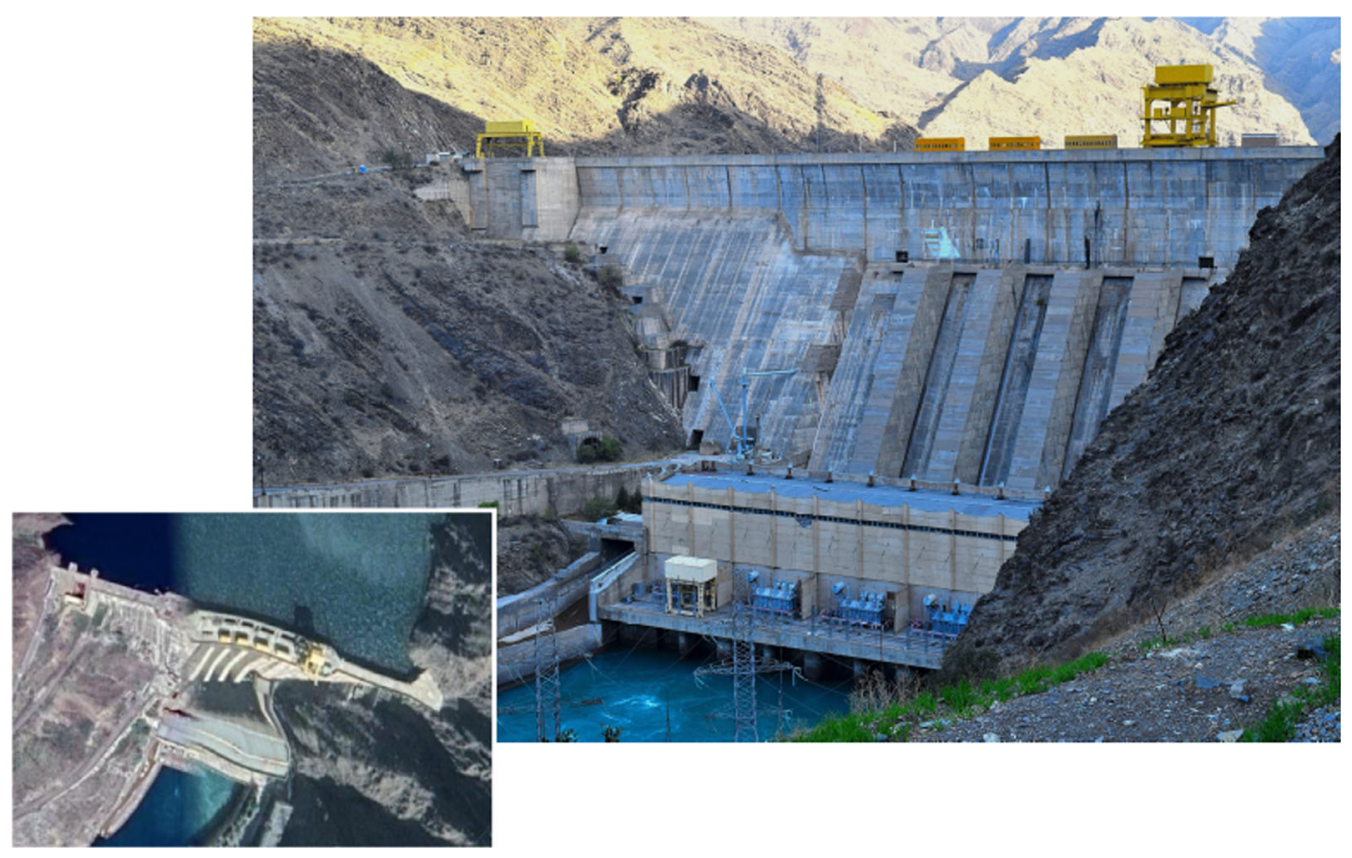

Figure 1

The Kurpsai dam as viewed from the south (the reservoir is to the north). Note the structure at the base of the dam is the power generation building. The seismic sensors were installed along the crest of the dam, on bedrock on both sides of the dam, and one just above the water way to the generator room (see Fig. 4). The inset shows a plan view. As can be seen, the dam has almost an east-west orientation (from Google Maps) 

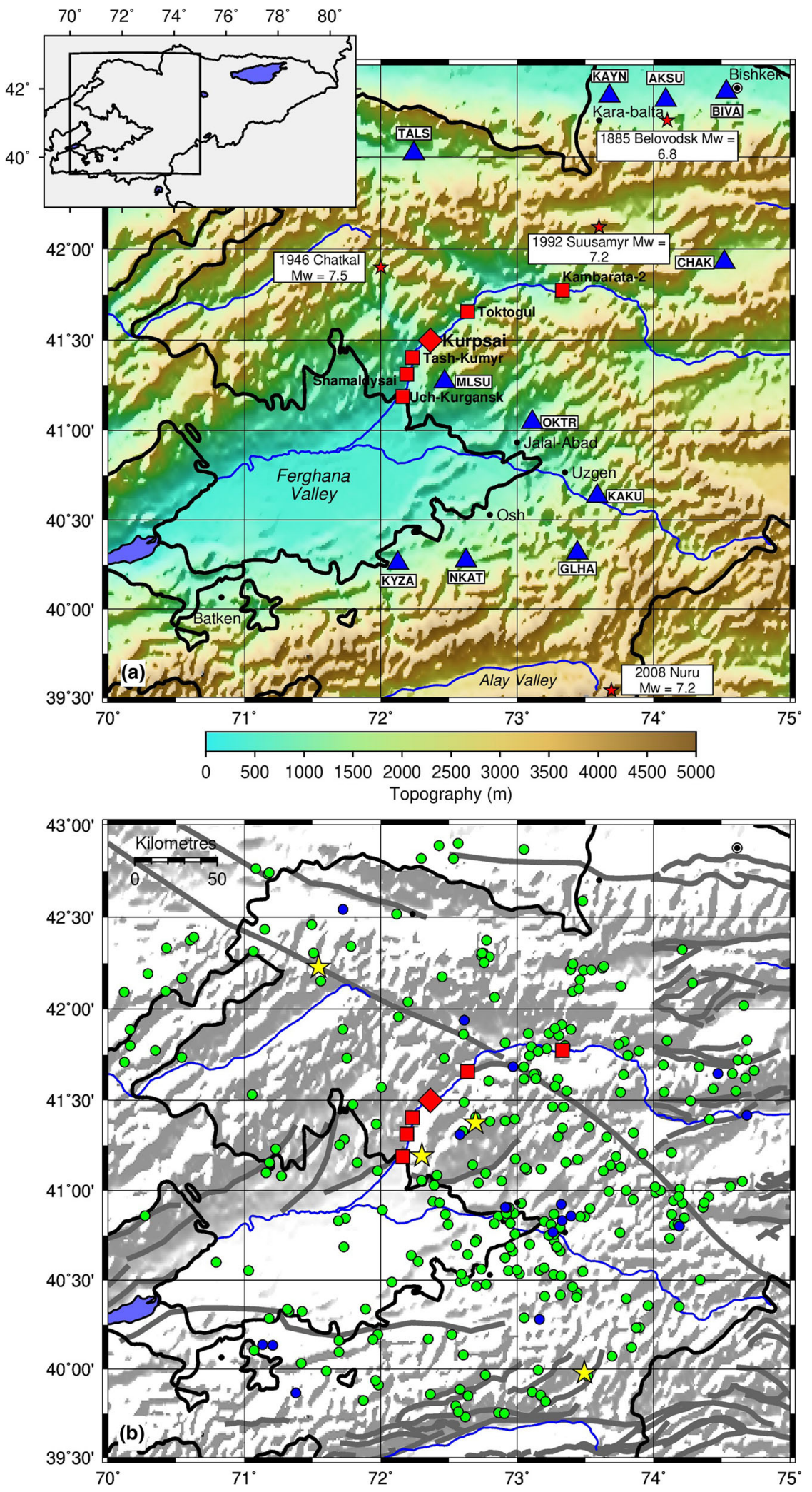
structural behaviour. Pagano and Sica (2013), for example, considered seismic monitoring for earth dams in Italy, while Koufoudi et al. (2018) employed modal analysis from observations provided by a seismic network around an arch dam in the French Alps to assess a finite-element model of the structure. In this work, we focus on the monitoring of variations in the dam's structure via seismic recordings and fibre-optic measurements between seasons, while from a set of small and moderate seismic records, we examine the impact such ground motion has on the dam's structure and the spatial variability of its response.

The next part of the paper describes the Kurpsai dam itself and the regional seismicity. This is followed by a summary of the instrumentation installed on the dam, after which some analyses of the various measurements are presented and interpreted. The results of these analyses are then discussed, with the conclusions presented, including proposals for future activities.

\section{The Kurpsai Dam and the Local Seismicity}

The Kurpsai dam (completed in 1981, Fig. 1) is one of six dams along the Naryn River (Havenith et al., 2015b; Kormev, 1981). It is a gravity dam with a maximum height of $113 \mathrm{~m}$, a crest length of $364 \mathrm{~m}$, and is divided into 13 sections. The resulting reservoir, which is regulated by the Toktogul hydropower station located upstream (Fig. 2a), has a total volume of 370 million $\mathrm{m}^{3}$, of which 35 million $\mathrm{m}^{3}$ is available for power generation. There are four generators in the installation, with a total capacity of $800 \mathrm{MW}$, leading to its annual production varying between 2600 and 3200 million kWh (Grunwald, 2012). Figure $2 \mathrm{a}$ also shows the locations of some examples of previous major events, of which the 1946 Chatkal and 1992 Suusamyr earthquakes are of particular relevance to this area (Kalmetieva et al., 2009). Furthermore, stations of the regional ACROSS seismic strong-motion network are shown, which, while being developed for early-warning purposes for the major urban areas of the Kyrgyz Republic, allows the tracking of the local seismicity (Parolai et al., 2017).
Figure $2 b$ shows the distribution of events of magnitude $\mathrm{M}>3$ between 01.09.2018 and 31.09.2019, as listed in the International Seismological Centre catalogue (International Seismological Centre, 2020. The magnitude corresponds to body wave magnitude $\mathrm{mb}$ ). A total of 267 events of magnitude $\mathrm{M} \geq 3$ were reported, 14 of which are of a magnitude $M \geq 4$, with the largest being $M=4.6$. Also marked is the Talas Ferghana fault, the largest strike-slip fault in Central Asia, which runs from the northwest to southeast and is only around $30 \mathrm{~km}$ north of the Kurpsai dam. However, its activity is still under debate. For example, Xu et al. (2006) comment that the central segment of the fault appears more active than the eastern part, which may be temporarily locked.

Due to water flow regulation by the Toktogul dam upstream, the water level of the Kurpsai reservoir changes very little throughout the year. As seen in Fig. 3, the headwater (reservoir level for the period 01.09.2018 to 31.08 .2019 , largely covering the study period) was $723.6 \mathrm{~m}$ a.s.1., with a standard deviation of $0.3 \mathrm{~m}$. For the tailwaters (i.e., the river level at the base of the dam), it is $629.1 \mathrm{~m}$ a.s.1., with a standard deviation of $1.0 \mathrm{~m}$. In terms of examining how a dam's behaviour varies with the water level, contrast this situation with that presented in Pereira et al. (2018), where a double-arched dam in Portugal was observed and variations in its natural frequencies identified as water levels changed over several-10's of metres. We, therefore, will not be considering the effect of the dam's level on its structural health.

As mentioned, there are four generators at the dam, with their use also shown in Fig. 3 using information provided by the Kurpsai dam management (personal communication). As one would expect, more generators are operated during the colder months. Considering Pearson's correlation coefficient $r$ between the two water levels, and between the water levels and generator operation, we find for the water levels a correlation of $r=-0.169$, the negative correlation expected as the higher headwater levels implies less water being released, although the actual correlation is very weak. Likewise, there is a negative correlation of $r=-0.155$ between the headwater level and the numbers of generators being operated, while a clearer positive 


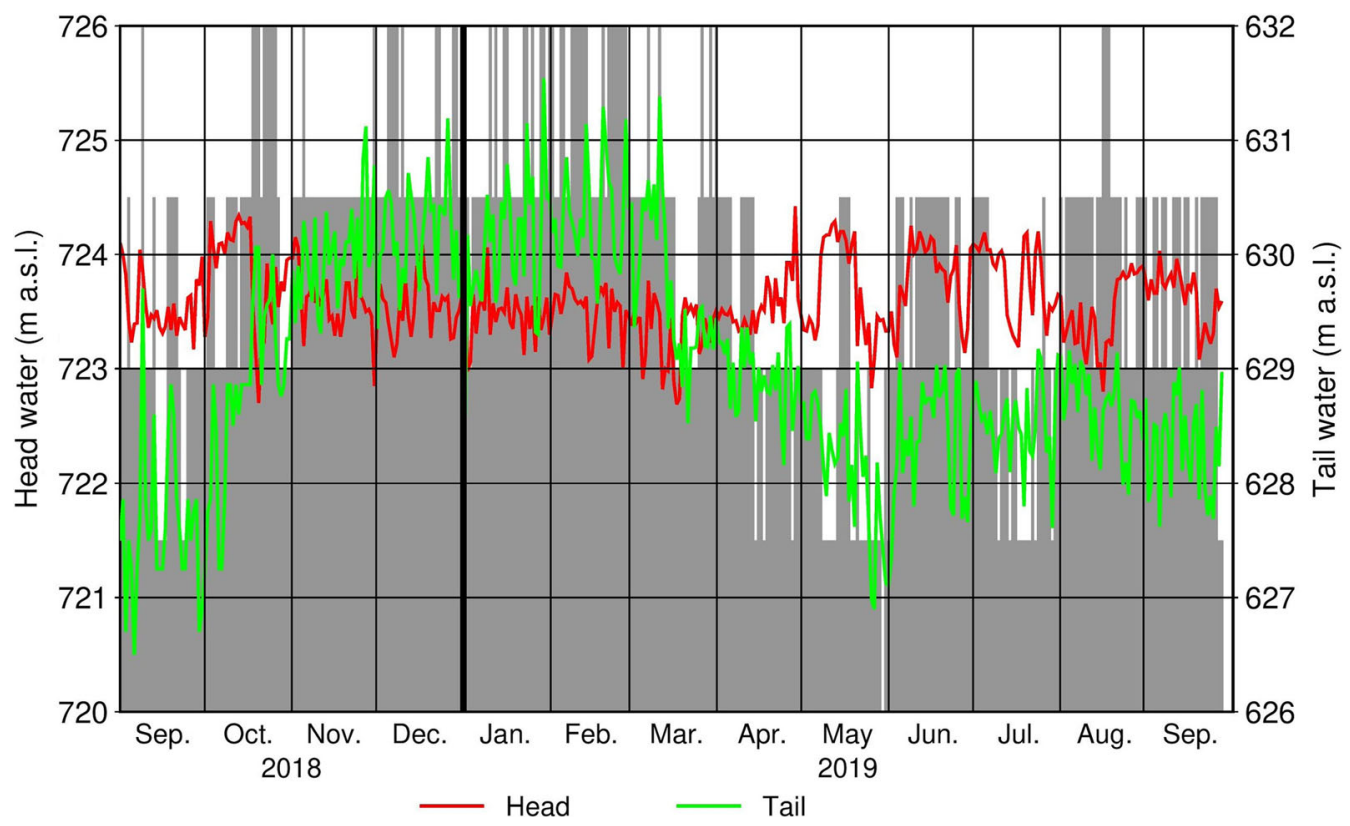

Figure 3

Comparing daily values for the head and tailwater levels (with respect to sea level) and the numbers of generators in operation during the study period (data provided by the Kurpsai dam management, personal communication)

correlation of $r=0.685$ between the tailwater level and the number of operational generators is found, expected as operating more generators means a greater amount of water being released, leading to higher tailwater levels.

When considering the generators and the water access tunnels (both sources of noise), the generators operate at one level, with a capacity of $200 \mathrm{MW}$ with 110 rotations per minute (Kurpsai dam management, personal communication) each, while the water running through the tunnels that feed the generators also have only one level, but will cover a wide range of noise frequencies. Hence, both sources of noise may be considered to have an off-on character. There is also an outlet tunnel on the western side of the dam, however, information specifically dealing with the amounts of water flowing through it and the times of use are not available, hence its contribution to the noise recorded on the dam cannot be considered in this study.

\section{Instrumentation Installed at the Kurpsai Dam}

\subsection{Seismic Monitoring}

The seismic sensors that were installed on the crest of the dam and surrounding slopes are termed MPwise (Multi-Parameter wireless sensing system, Boxberger et al., 2017). The MPwise units (a development from the SOSEWIN-Self-Organizing Seismic Early Warning Information Network, Fleming et al., 2009) are designed to be robust, relativelylow-cost, flexible, and easy-to-install units that mainly use off-the-shelf components and a modular design. The latter allows for different configurations of sensors and communication interfaces to be employed, depending on the circumstances. Although these units were originally designed for earthquake early warning, they have also been used in structural monitoring, e.g., assessing the state of a building before and after an event (e.g., Picozzi, 2012; Picozzi et al., 2011), and for site response assessment.

The current version of the MPwise hardware is made up of three primary parts: the digitizer board, the microcomputer and communications board, and 
Table 1

Technical specifications of the MPwise digitizer and microcomputer boards (Boxberger et al., 2017) and the velocimeters employed in this work

\begin{tabular}{ll}
\hline Digitizer board & \\
\hline Number of channels & 3 or 6 \\
AD converter resolution/effective resolution & 24 bit, typically 21.5 bit @ $100 \mathrm{~Hz}$ sps @ gain 1 \\
Gain & $1,2,4,8,16,32,64$ \\
Sample rate & $800(1 \mathrm{ch}-$ mode $), 400,200,100,50 \mathrm{sps}$ \\
Input impedance & $100 \mathrm{kOhm}$ \\
Input voltage range & $5-24 \mathrm{~V}$ \\
\hline
\end{tabular}

Microcomputer board

\section{CPU}

RAM (random access memory)

Operating system

Storage

Power consumption

IO Ports, Possible expansions

Connectivity

MEMS sensor
$1.8 \mathrm{Ghz}$ quad core ARM processor and $1.4 \mathrm{Ghz}$ quad core ARM processor 2Gbyte LPDDR3 RAM at $933 \mathrm{MHz}$

GNU/Linux

eMMC5.0 HS400 Flash Storage or micro-SD

3-5 W

30Pin: GPIO/IRQ/SPI/ADC

USB 3.0 Host $\times 1$, USB 2.0 Host $\times 4$, USB 3.0 OTG x, Ethernet RJ-45

$\pm 2 \mathrm{~g} / \pm 6 \mathrm{~g}$ user selectable full-scale, Acceleration noise density

$(\mathrm{Vdd}=3.3 \mathrm{~V} ;$ Full-scale $= \pm 2 \mathrm{~g}): 50 \mu \mathrm{g} / \mathrm{sqrt}(\mathrm{Hz})$

Velocimeter

Sensitivity

Response

Damping

Weight

Operating temperature
$28.8 \mathrm{~V} \mathrm{~s} / \mathrm{m}$

Ground velocity $4.5 \mathrm{~Hz}$ to $>150 \mathrm{~Hz}$ 0.56

$1 \mathrm{~kg}$ (including cable) -40 to $+100{ }^{\circ} \mathrm{C}$ the external sensors (Boxberger et al., 2017). The digitizer board includes a 6-channel analogue-todigital converter with 24-bit resolution, a GNSS (Global Navigation Satellite System) module for time marking and location information, and a sampling rate capacity of between 50 to 400 samples per second (sps). The microcomputer's duties involve the acquisition and storage of data, data processing and analysis, and communications. It consists of a multicore ARM processor ${ }^{1}$ and employs a micro-SD card (currently $32 \mathrm{~GB}$, but able to be expanded) for data storage. The communications hardware linked to the microcomputer board is made up of two omnidirectional dual-band antennas for WiFi communication and one omni-directional antenna for mobile communications. The sensors contained in each unit are 3-axis accelerometers using MEMS (Micro Electromechanical Systems) devices. The units can be complemented by other types of external units and

\footnotetext{
${ }^{1}$ ARM processor, http://www.arm.com/
}

may include standard strong and weak motion sensors, broadband sensors, and USB-connected devices such as video cameras, temperature and humidity sensors, and additional GNSS systems. In this work, velocimeters were employed. The flexibility offered by the MPwise units is obvious in how, by using multiple sensors, data types that complement ground motion measurements may help with identifying aspects of a structure's mechanical behaviour under different conditions, rather than using separate instruments, as is the usual case, including in this study. Some technical details of these units are listed in Table 1.

Seven MPwise units connected to velocimeters were installed on the dam, with 4 on the crest of the dam, one on each side of the dam on bedrock sites, and one located on a lower level (unit 24, Fig. 4a), with the sensors orientated with respect to the dam's crest. The bedrock sites were established to assess local seismic noise and the motion associated with seismic events, and to see how the dam's response 
(a)
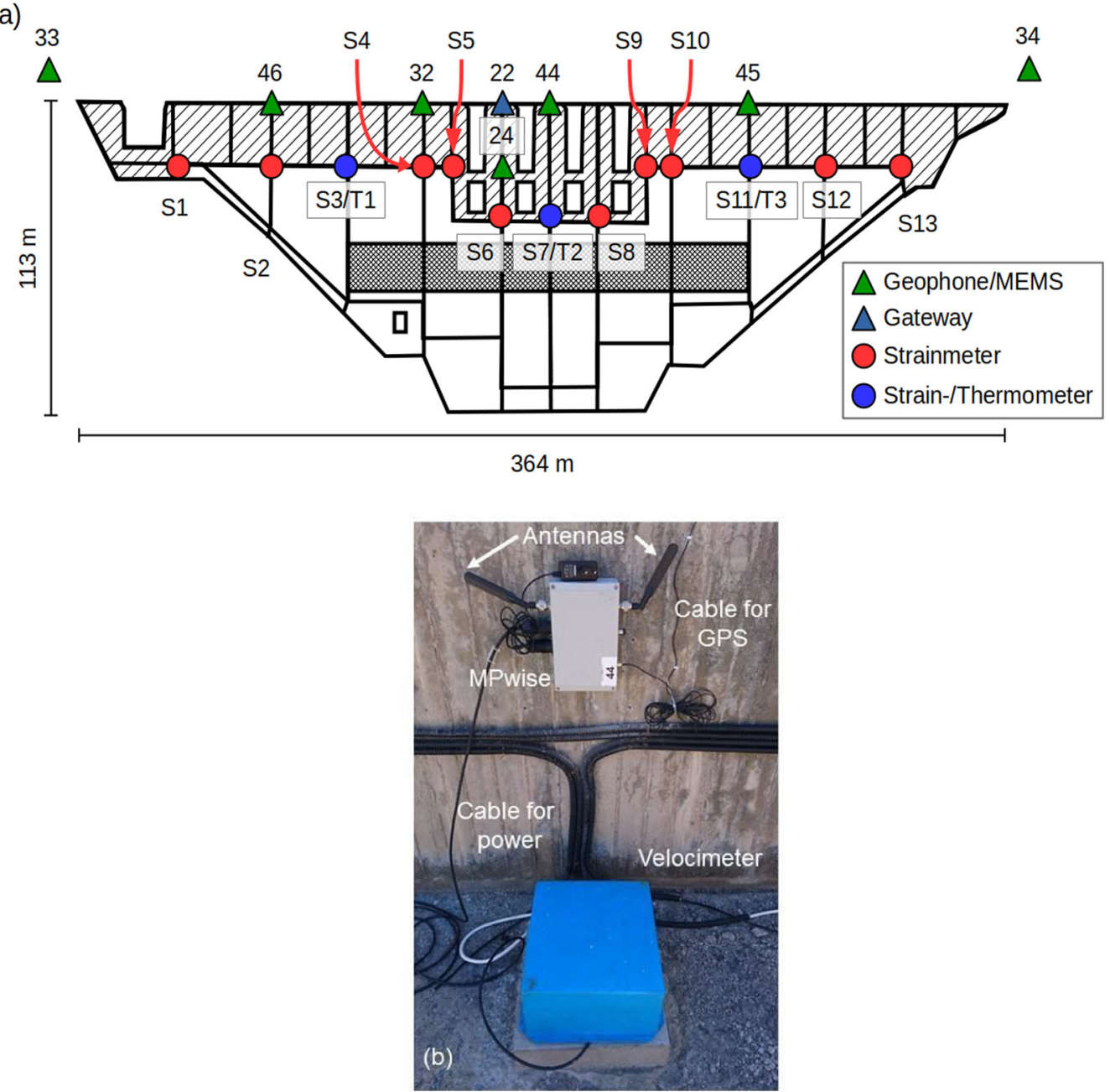

Figure 4

a The layout of the MPwise units (green triangles), temperature sensors (TX), and optical strainmeters (SX, circles) installed on the dam. Note: MPwise unit 22 (blue triangle) is only used for transferring the data to the internet gateway located in the dam's control room. MPwise units 33 and 34 are located on the bedrock on either side of the dam. b An example of a MPwise unit (44) with its external velocimeter installed on the Kurpsai dam

may propagate through to its surroundings. All units were set up to record continuously with a sampling rate of $100 \mathrm{sps}$. An additional unit without an external velocimeter was installed on the crest to serve as a communications gateway (unit 22 in Fig. 4a). This unit communicated with the other sensors and in turn transmitted their data to another unit (again without the external velocimeter, but using its internal MEMS-based 3-component accelerometer) which was installed in the nearby control/administration building, from where it was distributed via the internet to the Central Asian Institute for Applied Geoscience (CAIAG) in Bishkek, and the GeoForschungsZentrum (GFZ) in Potsdam in realtime. Owing to technical difficulties, there are frequent gaps in the time series, with the completeness of each unit's data set ranging from $84.7 \%$ for unit 45 , to $31.3 \%$ for unit 33 over the period 24.08.2018 to 23.12.2019. Figure 5 shows the completeness of the record for sensors 45 and 33 as examples. There was only limited data obtained from unit 24 , located on a lower level from the crest, owing 

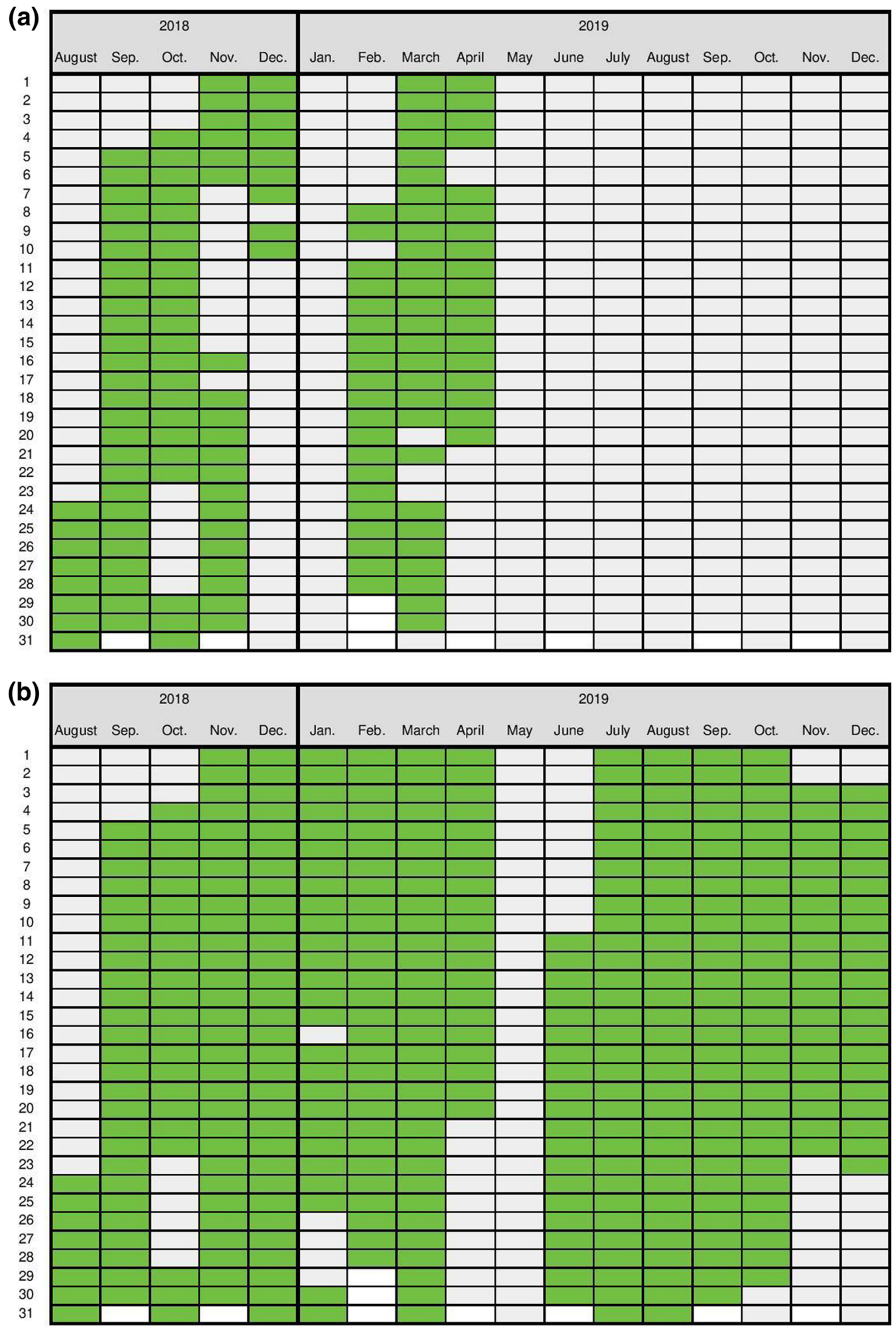
Figure 5

Examples of the completeness of the data series recorded by the MPwise units on the Kurpsai dam (see Fig. 4a), with days where data is available marked in green. a Unit 33, with a completeness $31.3 \%$ and b unit 45 with a completeness of $84.7 \%$. Note that the data may not be complete for a given day even if some is recorded

to a lack of connectivity. Note, there were also sometimes gaps during some days, thus Fig. 5 only indicates that there was some data provided by that sensor for that day. The reasons for these gaps are varied, ranging from the sensors failing due to the harsh climate conditions (highly continental climate), as well as daily operations interfering with the communications (moving cranes, vehicles, etc.).

\subsection{Fibre-Optic Strainmeters and Temperature Meters}

A total of 13 fibre-optic strainmeters were bolted between the concrete blocks that make up the Kurpsai dam for measuring the static strain. At three of these locations, a fibre-optical temperature sensor was colocated (Fig. 4a). This type of instrumentation of the dam was intended to ensure the continuous measurement of strain and the opening and closing of joints between the individual concrete blocks. The temperature sensors were used to compensate for the temperature drift of the strain sensors during data acquisition.

The optical sensors were installed in two arrays of (1) five strainmeters of type HBM FS62, with one colocated temperature sensor (HBM FS63) and (2) eight strainmeters (HBM FS62) and two temperature sensors (HBM FS63). The optical strainmeters have a range of $\pm 2500 \mu \mathrm{m} / \mathrm{m}$ and a resolution of $1.5 \mathrm{pm}$. The sensors were sampled at a frequency of $1 \mathrm{~Hz}$ by a HBM FS22 interrogator ${ }^{2}$, with the sampling frequency being the optimal value for static measurements using optical sensors. At acquisition time the measured static strain was corrected for the static instrument offset and temperature drift was

\footnotetext{
${ }^{2}$ https://www.hbm.com/en/4604/fs22-industrial-braggmeteroptical-interrogator/
}

compensated using the three co-located installed temperature sensors.

The strain and temperature sensors recorded data from 01.09.2018 to 18.09.2019, after which no further data was available owing either to communications issues or the sensors themselves failing. Sensor ST02 malfunctioned at the beginning of the project and therefore did not report any data, while other sensors had occasional periods where corrupted data were recorded, with again periods when the acquisition was suspended completely, as with the MPwise units.

\section{Seismic Signal Analysis}

\subsection{Seismic Noise Analysis}

Analysing the seismic noise recorded by the sensors located on the dam and the reference rock sites on either side of the structure (sensors 34 and 33 in Fig. 4a) allows the fundamental and several higher modes of vibration of the dam to be identified. Since short time series were often affected by disturbing signals, the natural frequencies or eigenfrequencies of the dam were estimated by applying a statistical approach based on the power spectral density (PSD) functions (McNamara \& Buland, 2004). From noise time series recorded at 10 days for $30 \mathrm{~min}$ at both night time and daytime, we removed the mean and we applied a digital Butterworth filter with passband between 0.1 and $35 \mathrm{~Hz}$. Each time series was divided into smaller segments of $40 \mathrm{~s}$ overlapping by $75 \%$ to reduce the variance in the PSD calculation (Cooley and Tukey 1965). We furthermore applied a 5\% cosine taper to reduce the spectral leakage. From the spectrum of each segment, the instrumental response has been removed. The total power, representing the PSD estimate, is obtained from the square of the amplitude spectrum multiplied by the standard normalization factor $2 /(N s)$, where $s$ is the sampling rate and $N$ is the number of samples.

The resulting PSDs for the dam-vertical component for the sensors on the dam and the reference bedrock sites are shown in Fig. 6. From recordings on the dam, a fundamental frequency of vibration of around $3.3 \mathrm{~Hz}$ can be easily identified with larger 

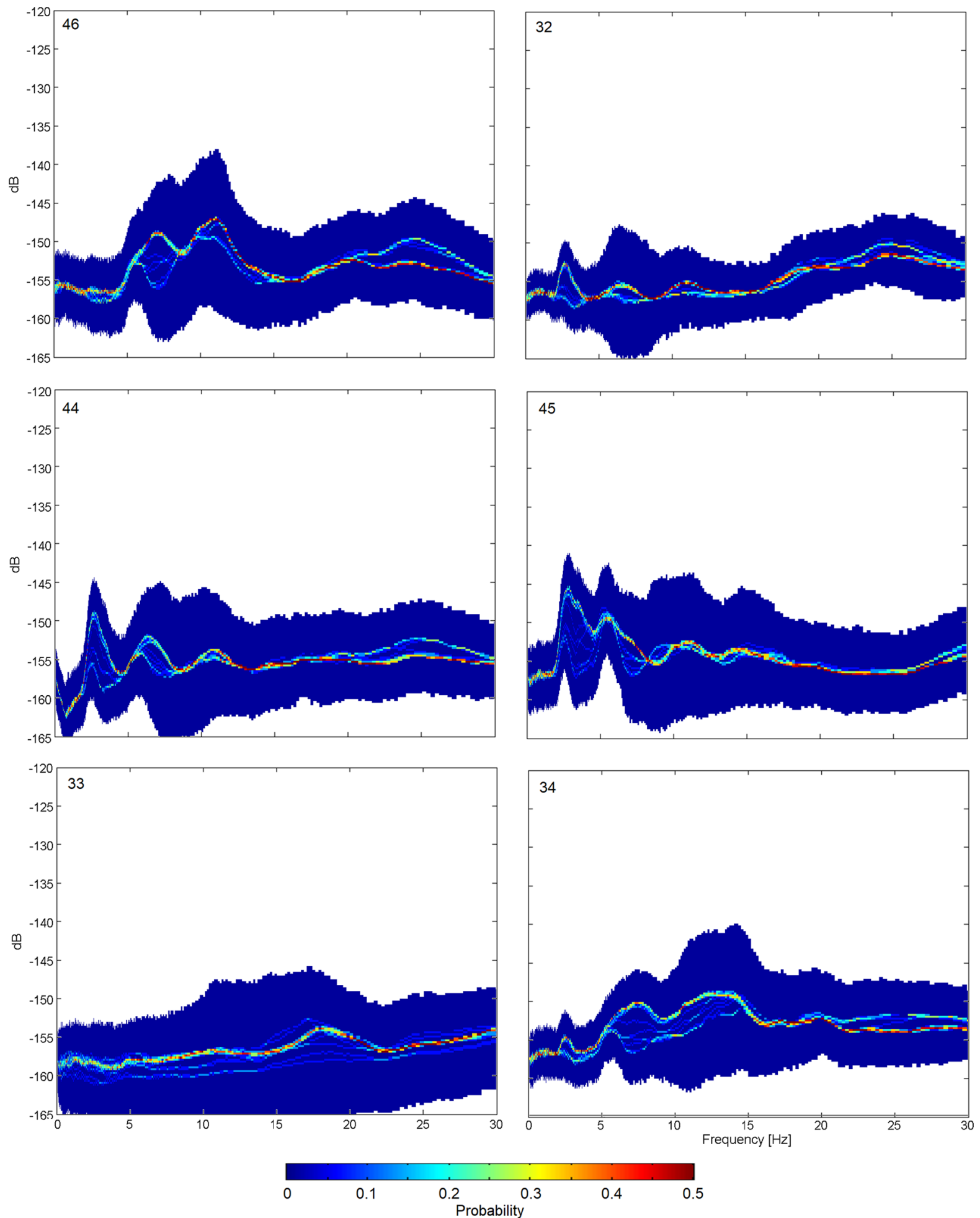
Figure 6

PSD functions represented by power density functions for sensors on the top of the dam (see Fig. 4a for their respective locations): 46 (top left), 32 (top right), 44 (middle left), 45 (middle right) and 33 (bottom left) and 34 (bottom right, see Fig. 4a) for the components perpendicular to the dam

amplitudes for the sensors in the central part of the dam. On the horizontal components, with the amplitude of vibration is significantly stronger in the direction perpendicular to the dam's structure (not shown). Secondary peaks with generally decreasing amplitudes are found at around $6 \mathrm{~Hz}$, followed by another modular peak at $11 \mathrm{~Hz}$. Sensor 46, however, shows higher amplitudes for the higher modes of vibrations, probably due to some weakening of the fundamental mode of vibration towards the edges of the dam. The vibration of the dam does not appear to significantly influence the wavefield on the western slopes (sensor 33) while on the western side (sensor 34), the dam's modular peaks are visible. Although the PSDs are rather smooth, soil resonance effects due to weathered surface layers appear to cause some minor amplification effects in the high-frequency range between 10 and $20 \mathrm{~Hz}$ while these effects are believed to not be caused by the dam structure.

\subsection{Seasonal Analysis}

The next analysis involved assessing how the spectra of the dam's response to noise varied during the year as a function of the seasons. The climate of the surrounding study area is highly continental, with a mean annual air temperature of $12.8{ }^{\circ} \mathrm{C}$, maximum and minimum temperatures of around $+44{ }^{\circ} \mathrm{C}$ and $-30{ }^{\circ} \mathrm{C}$, respectively, and an annual average precipitation of $378 \mathrm{~mm}$ (Kormev, 1981). Ideally, there would be continuous data covering an entire year so as to assess seasonality in the structure's behaviour, which has been shown to be sufficient in other structural monitoring studies (e.g., Kita et al., 2019). Unfortunately, because of the above mentioned communication difficulties, there are gaps in the data, as shown by Fig. 5, for example, from late-May until early-July 2019. There is also the situation where the numbers of generators being operated varies (see Fig. 3) whose contribution to the noise experienced by the dam must be considered. Therefore, we have considered two shorter periods (i.e., several days) in November 2018 and July 2019, representing winter and summer conditions, respectively, where the number of generators being used was stable, i.e., during the winter segment, three generators were operating, while during the summer segment, one was running, to see if there are changes in the response of the dam to noise as a function of temperature.

Spectrograms showing the PSD were calculated for the considered winter (Fig. 7a) and summer (Fig. 7c) periods. The spectra window is $100 \mathrm{~s}$ long, with $75 \%$ overlap. Clearly visible in these figures are periods of higher and lower seismic noise at the dam, where during certain hour-long periods, particularly in the summer, less spectral energy is observed. The noise is strongest in the $3-6 \mathrm{~Hz}$ band, with apparent higher modes visible in the data, corresponding to the frequency ranges with higher spectral amplitudes identified in Fig. 7a.

For each sensor, the average spectral power $P_{C u m}$ was retrieved by first correcting the instrument response of the geophone. The time series were then bandpass filtered between 1 and $25 \mathrm{~Hz}$ with a secondorder Butterworth filter. Correspondingly,

$$
P_{\text {Cum }}=\frac{1}{N} \sum_{w=0}^{N}\left|S_{x x}(\omega)\right|^{2}
$$

where $N$ is the number of samples in the trace and $S_{x x}(\omega)$ is the complex Fourier transform of the filtered seismic trace. The average spectral power was calculated within cosine-tapered 20-min traces. The results cover the same periods for winter (Fig. 7b) and summer (Fig. 7d) and are compared to the temperatures recorded on the outside of the dam facing south and within the dam inside a maintenance and access tunnel (see Fig. 4a).

We see that the level of noise is generally higher in winter than in summer. We note that for summer, the three vertical "strips" that show lower power in Fig. 7c (yellowish colour) lasting a few tens of minutes up to a few hours correspond to the periods of lower spectral power in Fig. 7d. As discussed above, according to the Kurpsai dam management (personal communication), different numbers of 


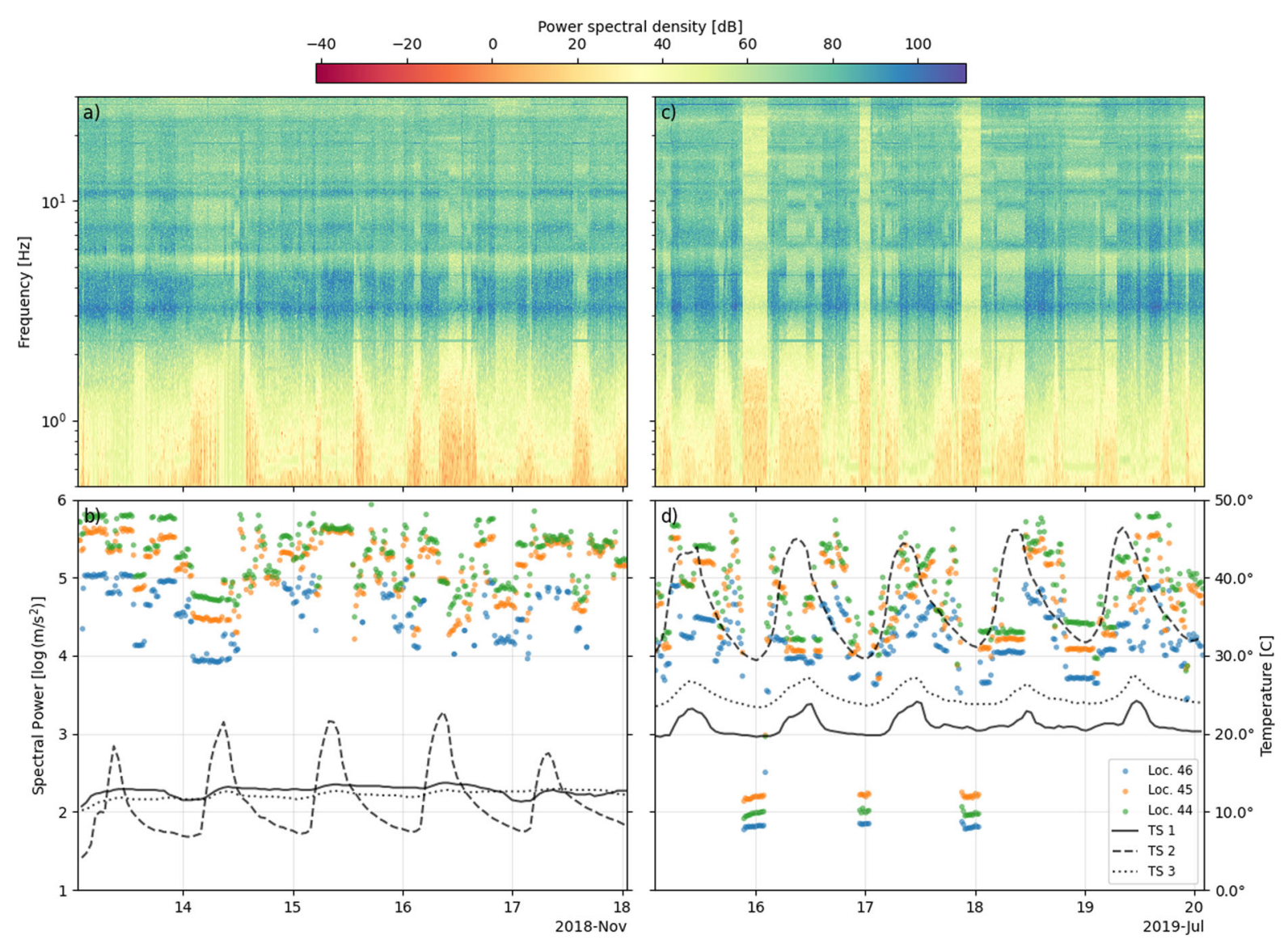

Figure 7

Data recordings covering 5 days in winter (13 to 18 November 2018, (a) and (b)) and summer (15 to 20 July 2019, (c) and (d)). The spectrograms (a) and (c) show the seismic energy on the vertical component between 0.5 to $30 \mathrm{~Hz}$ at sensor 44 (see Figs. $4 \mathrm{a}$ and 6). Average seismic energy (b) and (d) recorded on the vertical component by three seismic sensors (46, 45, and 44, see Fig. 4a) installed on the dam (orange, blue and green dots, respectively). The temperature measurements inside and outside the dam (TS1—inside an access tunnel, T2 —at the entrance to a tunnel, TS3 - outside on the dam facing south) from (b) winter and (d) summer. The x-axis is in UTC

generators operate at different times, wherein these examples and as discussed above, more generators were operating during the winter period than during the summertime. However, as is apparent from Fig. 3, the operational record of the generators is only available with a daily resolution. Since turning on and off the turbines can be done within ten minutes (Kurpsai dam management, personal communication), any variations in the power of the seismic noise over timescales of hours may be the result of varying the flow of water through the inlet tunnels due to the changing numbers of operating generators. Since phases of low energy can be found mostly during night time, it seems very likely that these phases correspond to time ranges during which the amount of water passing through the tubes and turbines is significantly reduced or even stopped.

\subsection{Operational Analysis}

One aspect that is of interest is how the dam responds during the day with respect to the operational activities being carried out in and around it. This includes not only the number of generators being operated, as discussed in the previous section, but also general work around the dam. For example, from Fig. 1 one can see cranes on the crest of the dam, whose operation would be expected to contribute to 
the general noise recorded by the sensors during working hours. We, therefore, analysed the probabilistic PSD over a 24-h period averaged over a whole year, minus the gaps in the data (Fig. 8). The probabilistic PSD allows the assessment of the statistical distribution of noise levels across the frequency spectrum (McNamara \& Buland, 2004). We see that there are peaks from around 7 to 11 in the morning and 7 to 10 in the evening (local time). This corresponds to periods of greater activity about the dam and (on average) during peak power usage times (people starting and ending the days in their homes, leading to higher electricity consumption and thus more generators in use). This again suggests the numbers of generators operating, hence the total amount of water running through the dam during the day, might vary.

\subsection{Event-Specific Analysis}

For the long-term structural safety of any structure, especially strategic infrastructures such as hydropower dams, it is of broad interest to understand how they respond during earthquake-induced strong ground motion. However, during the last few years covering the period where observations were being made, only a moderate level of seismicity has been recorded around the dam (see "The Kurpsai Dam and the Local Seismicity" and Fig. 2). To verify if any degradation can be observed, our analysis procedure is based on the approach proposed by Astorga et al.
(2018). The nonlinear elastic response of the dam was studied by monitoring the co-seismic variation of its fundamental resonance frequency. To obtain the time-frequency distribution of the signal's energy, we consider a smoothed windowed version of the classical Wigner-Ville (WV) distribution for the analysis of nonstationary signals. The windowing function $h$ helps avoid problems due to signal interferences, while the smoothing function $g$ allows an independent control in both the time $t$ and frequency $\omega$ domains of the applied smoothing. The corresponding WV distribution $P$ of a signal $x$ to be analysed is provided by Auger and Flandrin (1995) and has been adapted by Michel and Guéguen (2010):

$P(t, \omega)=\int_{-\infty}^{\infty} h(\tau) \int_{-\infty}^{\infty} g(s-t) x\left(s+\frac{\tau}{2}\right) x\left(s-\frac{\tau}{2}\right) d s e^{-2 \pi i \omega \tau} d \tau$

with $g$ and $h$ representing regular windows corresponding to the time and frequency smoothing, and $x^{*}$ being the complex conjugate of $x$.

By analysing the time-frequency distribution for each strong-motion event, we were able to monitor variations in the structural response by variations in the fundamental frequency over time. Hereunto, for each seismic event, means and trends were removed from the recorded time series and a second-order Butterworth filter was applied between 1 and $50 \mathrm{~Hz}$, with the latter frequency corresponding to the Nyquist frequency of the observations. As an example, Fig. 9 shows the temporal evolution of the

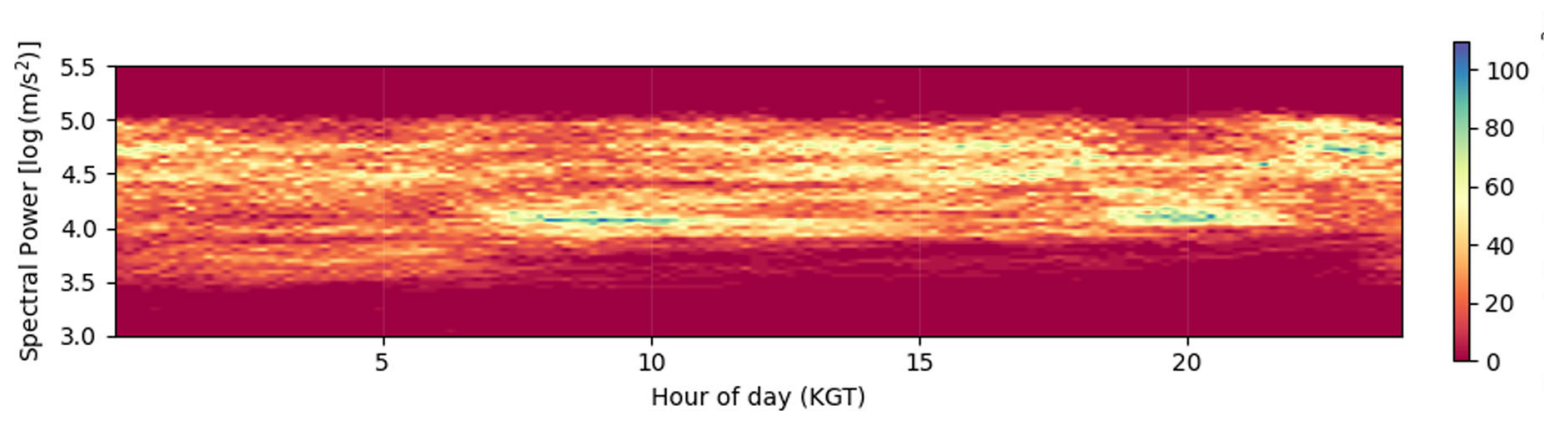

Figure 8

Mean seismic spectral power density over $24 \mathrm{~h}$ (local Kyrgyzstan Time, KGT) on the vertical component of sensor 22 covering one year (excluding gaps) of seismic data from 05.09.2018 to 05.09.2019 

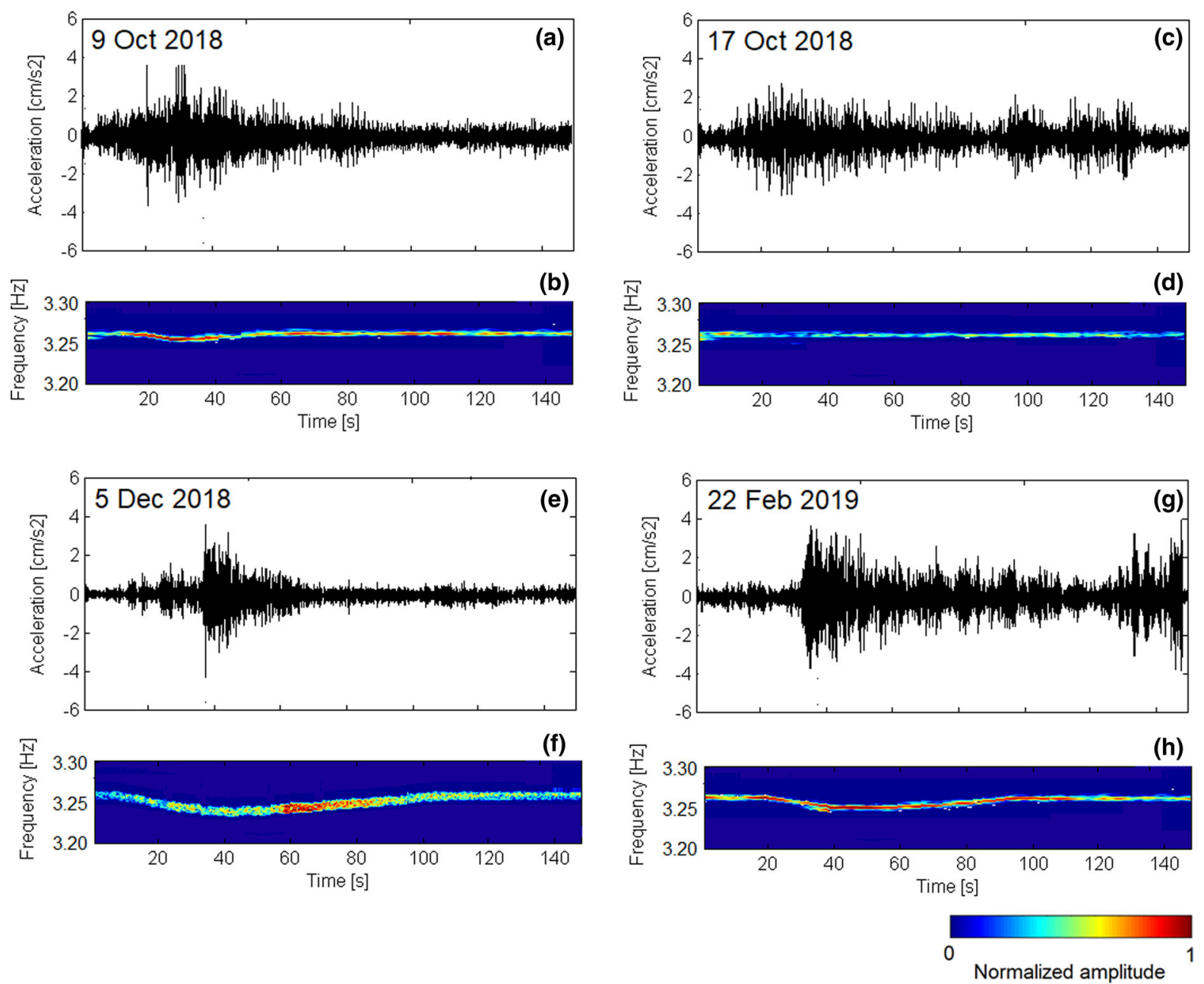

Figure 9

Time-history (north-south, i.e., perpendicular to the dam crest, component) and corresponding variation of the fundamental resonance frequency (normalized amplitude) as observed through the Wigner-Ville distribution for sensor 44 (see Fig. 4a). (a), (b) 9 October 2018 event. (c), (d) 17 October 2018 event. (e), (f) 5 December 2018 event. (g), (h) 22 February 2019 event

minimum value of the fundamental frequency during four moderate shaking events, listed in Table 2 as observed by sensor 44 . This sensor was selected because it is located in the central part of the dam, and shows the strongest response to seismic shaking.

The apparent initial frequency of $3.27 \mathrm{~Hz}$, as identified in Fig. 6, corresponds to the elastic frequency of the dam before the arrival of the seismic waves. For the events with stronger shaking (i.e., large PGA values for the events on the 05.12.2018 and 22.01.2019, Table 2), this frequency value decreases marginally to a minimum value of $3.23 \mathrm{~Hz}$ during the strongest shaking within a few tens of seconds. This is caused by the co-seismic softening of the dam resulting from the increasing number of small cracks opening and closing during the shaking (similar to, e.g., Astorga et al., 2019). The reservoir water interacting with the dam places an additional load of hydrodynamic pressure on one side of the dam during strong shaking, further contributing to the frequency shift. With decreasing shaking intensity, a nonlinear recovery process starts and the fundamental frequency returns to its initial value fairly quickly (i.e., within a few tens of seconds). For weaker events, the decrease in the fundamental frequency is less significant or hardly observable 
Table 2

The four events used for the lagged-coherency analysis (see Fig. $2 b$ for the location of the events)

\begin{tabular}{llllll}
\hline ISC designation (Event ID) & Date (UTC) & Magnitude (mb) & Location (Long. / Lat.) & Distance from the dam (km) & PGA $\left(\mathrm{cm} / \mathrm{s}^{2}\right)$ \\
\hline 614587176 & $09.10 .2018,01: 41$ & 3.3 & $73.4926^{\circ} \mathrm{E} / 39.9777^{\circ} \mathrm{N}$ & 194 & 3.8 \\
614587541 & $17.10 .2018,04: 37$ & 3.5 & $72.3013^{\circ} \mathrm{E} / 41.1914^{\circ} \mathrm{N}$ & 35 & 2.9 \\
614406046 & $05.12 .2018,22: 17$ & 4.5 & $71.5438^{\circ} \mathrm{E} / 42.2281^{\circ} \mathrm{N}$ & 106 & 4.2 \\
615024569 & $22.02 .2019,17: 31$ & 3.7 & $72.6955^{\circ} \mathrm{E} / 41.3747^{\circ} \mathrm{N}$ & 31 & 3.9 \\
\hline
\end{tabular}

(e.g., the 17.10.2018 event). In laboratory experiments, it has even been shown that there exists a threshold value below which the material behaves in a linear-elastic manner, i.e., no shift in the resonance frequencies can be observed below this threshold (Johnson \& Jia, 2005). For all analysed (moderate) seismic events during the one-year study period, an immediate recovery of the fundamental frequency to a constant value of $3.27 \mathrm{~Hz}$ was observed, reflecting that no permanent structural damage can be identified resulting from these events.

To analyse any differences between the seismic ground motion recorded at different locations over extended structures such as dams, we examined the spatial variability of the recordings. Differences in the way seismic waves interfere when arriving from a distant source will cause incoherencies in phase content and in the amplitude of the ground motions at two distant (several hundred metres) points. Moreover, the scattering effect, i.e., the combination of multiple waves refracted or diffracted by structural and/or topographic heterogeneities along their propagation path from the source to the sensor, further contributes to these phase incoherencies.

There are several ways of describing motion coherency (e.g., Abrahamson, 2005), while in this work we employed the lagged-coherency method. This involves describing the coherency measured after aligning the time series using the time lag that leads to the largest modulus of the cross-spectrum between the recordings at two sites. There is no requirement for consistent time lags for the various frequencies. Assuming that the seismic wavefield can be modelled by a plane wave passing through the dam structure (which is reasonably fulfilled given the hypocentral distance of the analysed events), the cross-spectral density of motion at two sensors, $i$ and $j$, can be written as:

$$
C_{i j}(\omega)=\frac{S_{i j}(\omega)}{\sqrt{\left[S_{i i}(\omega) S_{j j}(\omega)\right]}}
$$

where $S_{i j}$ describes the cross-spectral density at frequency $\omega, S_{i i}$ and $S_{j j}$ represent the corresponding auto-spectral densities, and $C_{i j}$ is the coherence between two arbitrary motions (i.e., motion at sensors $i$ and $j$ ) and a measure of the similarity between these two points, including both the phase spatial variation and the passage of the wave. For high frequencies and/or long inter-sensor distances, the motions will become uncorrelated, and the lagged coherency will tend to zero due to diminishing $S_{i j}$. While some studies have used a transformation process $(i j)$, we do not follow this approach since this requires the spectrum of the process to be constant over the entire frequency bandwidth of the window, meaning that a bias will be introduced if this is not the case.

To be consistent with the incoherence function, the lagged coherency is calculated on the strong motion window using an 11-point Hamming window as suggested by Abrahamson et al. (1991). This value has been found to provide the best results for structural analysis for relatively short time windows (less than 2000 samples, i.e., in our case, $20 \mathrm{~s}$ ) and a damping coefficient of $5 \%$. A bias is introduced at higher frequencies and long separation distances due to the use of finite length series that may produce finite values for the estimate when the true coherency is zero (Zerva, 1999). As an example, Fig. 10 presents the lagged coherency between each pair of MPwise sensors installed on the dam for the two horizontal components. These components are evaluated from the portion of the records covering the strong $\mathrm{S}$ wave motion, and the resulting coherence values from considering the four events discussed (Table 2) are averaged. For vertical coherencies (not 

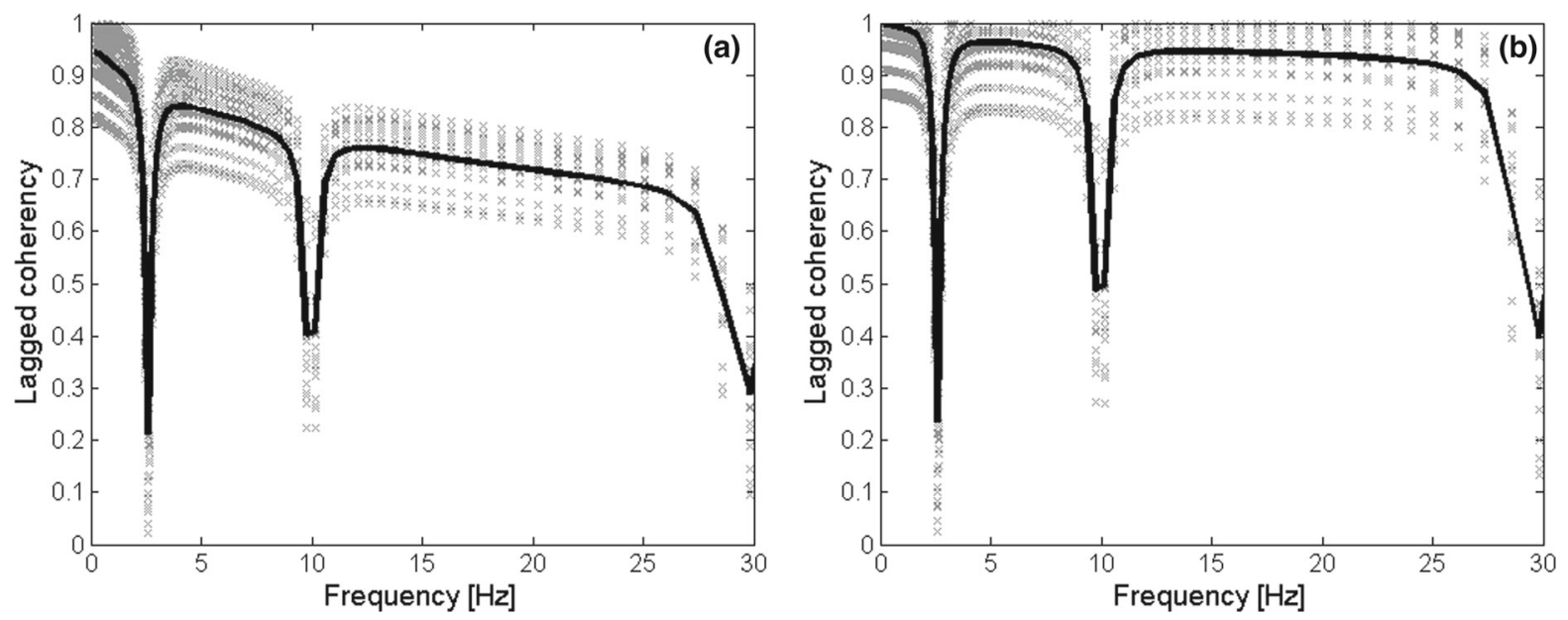

Figure 10

Lagged coherency for the S-wave window a perpendicular and $\mathbf{b}$ parallel to the dam crest between different sensor pairs and the four events listed in Table 1 (see Fig. 2b). The thick black line represents the mean of all pairs

shown here), a similar conclusion can be drawn, although the vertical amplitudes for increasing frequencies are lower by around $30 \%$.

The lagged-coherency values show a significant loss of coherency within several narrow frequency bands for both horizontal components. The loss of coherency around the resonance frequencies of the dam at around $3.3 \mathrm{~Hz}$ and around $10.5 \mathrm{~Hz}$, as identified in Fig. 6, indicates that the presence of the large dam structure significantly influences the phase content of the ground motion associated with each event, showing that there is some reduction in the in-structure response due to motion incoherency effects. Several studies (e.g., Bi \& Hao, 2009; Zerva \& Harada, 1997) have shown that there is a decrease in the coherency function in the vicinity of frequencies where the spectra are amplified. The time delays caused by the apparent propagation velocity results in out-of-phase motions at the dam's resonance frequencies. Hence, as seen in Fig. 10, a loss of coherency is seen over the frequency ranges where the stronger amplification of the Fourier spectra occurs, confirming that the structure increases locally the spatial variability of the ground motion. The overall loss of coherency with increasing frequency is negligible due to a lack of other sources of incoherence in the medium, apart from the presence of the structure. The observed general trends for the dam's parallel and perpendicular components of ground motion are comparable, although the motion is less coherent perpendicular to the dam crest. A possible explanation for this behaviour could be that the dam is composed of 13 structural blocks linked by slightly flexible joints which causes some distortion of the coherent movement.

\subsection{Strain Analysis}

The static strain measured between the 13 structural blocks shows a signal that is strongly correlated with temperature (Fig. 11). As can be seen from this figure, and as mentioned above ("Fibre-Optic Strainmeters and Temperature Meters"), there were several gaps in the time series. Nonetheless, we can identify a clear 24-h cycle with amplitudes ranging from \pm 20 $\mu \mathrm{m}$ for the strain sensors located inside the dam to $\pm 750 \mu \mathrm{m}$ for those located on its outside surface. A long-period seasonal signal can also be identified by all sensors, where the amplitude of the variability is much greater in summer than in winter.

\section{Discussion}

Based on the analysis of seismic recordings made on the dam's crest, we see the horizontal component 

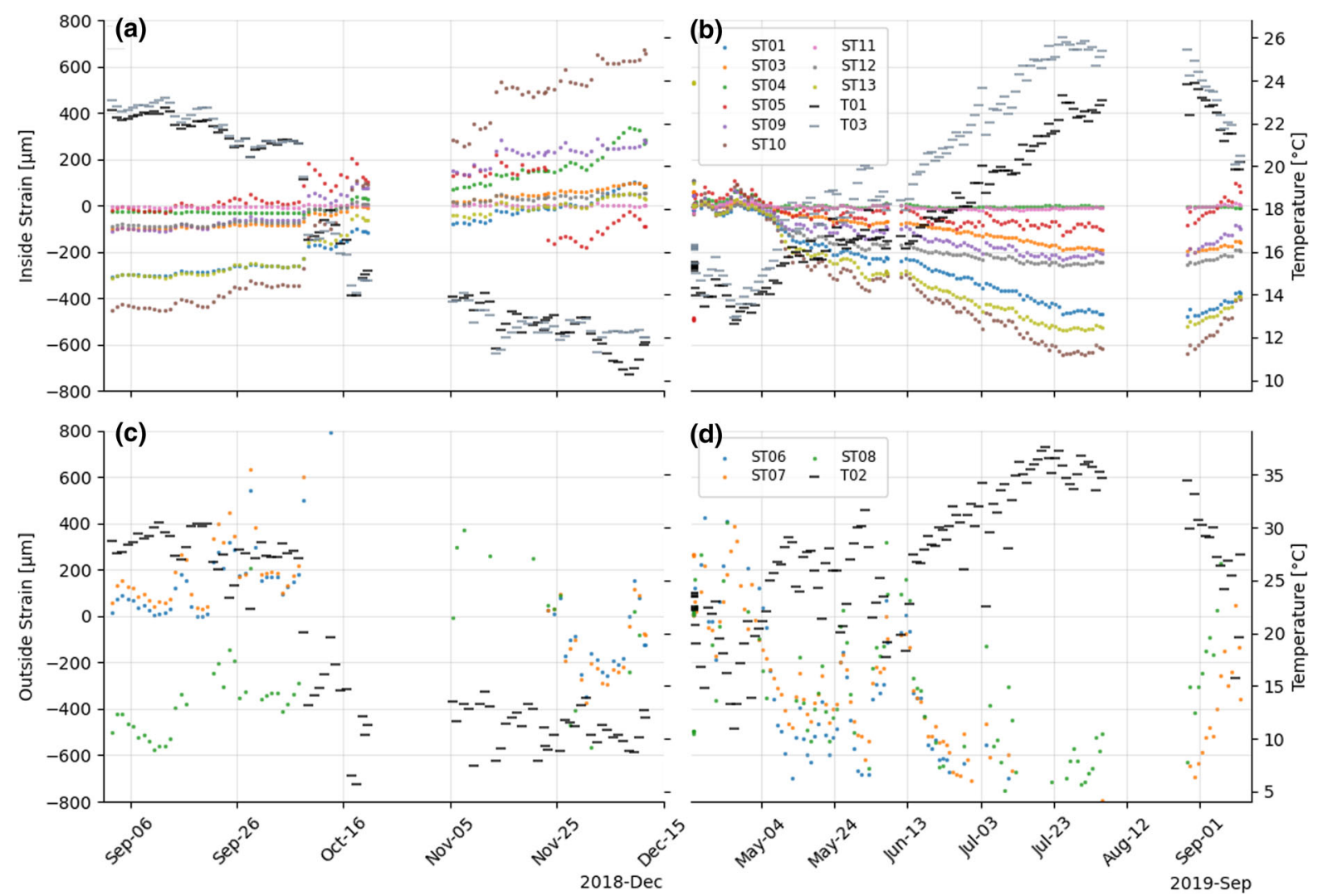

Figure 11

Static strain data from the fibre-optic strain sensors between the dam's structural blocks. a Strain meters inside the dam's tunnel from September to December 2018 and b from April to September 2019. c Strain meters mounted outside on the dam's terrace (see Fig. 4a) from September to December 2018 and d from April to September 2019. The strain data has been corrected for a zero offset and temperature compensated using the three temperature sensors T1, T2 and T3. The temperature values of the tunnel sensors T1 and T3 are shown as black and grey lines in (a) and (b). Outside temperature values measured by sensor T2 are shown as black lines in (c) and (d)

of motion revealed three peaks, namely at $3.3,6$, and $11 \mathrm{~Hz}$, while in the vertical component, only the 6 and $11 \mathrm{~Hz}$ peaks were apparent. Similar results were seen from the coherency analysis (Fig. 10). The $3.3 \mathrm{~Hz}$ fundamental frequency was seen to decrease by $1-2 \%$ because of ground motion induced by nearby moderate-sized (M 3.7 and 4.5) earthquakes (Fig. 9), but quickly recovered to its original state within minutes after the strongest shaking had ended. We interpret this as being caused by the smaller cracks within the dam opening but closing immediately. The question would then arise as to how much the fundamental frequency of the structure would vary after a significantly stronger event than those examined in this work, and how long would be required for the dam to recover. It is expected (e.g.
Astorga and Gueguen, 2020) that with increasing density of cracks (i.e., increasing level of damage), the structural response will be less dependent on the input motion and it will be governed more by the long-term degradation and by the degree of cracking. Placing sensors in strategic locations (i.e., one sensor for each of the 13 structural blocks) might allow both the local response as well as the coherency of groundmotion to be resolved more clearly.

Changes in the power of the seismic vibrations have been identified throughout the year (in particular, between winter and summer) and during the day. The reasons behind these variations are tentatively put down to the work activities being conducted around the dam (e.g., movement of the cranes, vehicles, elevators within the dam) and, in particular, 
on the number of generators in operation, although it is not certain if this change in the noise level is due to the operation of the generators themselves (housed in a separate building, see Fig. 1), or due to the amount of water moving through the intakes to the generators. Unfortunately, there are no records available concerning the amount of water moving through these outlets or how the numbers of generators operating during the day varies. One feature not examined in detail was the influence of the changing level of the reservoir, which has been the subject of other works (e.g., Pereira et al., 2018). However, as discussed above (Fig. 3), the actual level of the Kurpsai reservoir varies by only a small amount (standard deviation of around $0.3 \mathrm{~m}$ over a year), therefore, we consider the reservoir level to have a negligible effect on the dam's response to seismic and other noise.

The strain data appears to reflect changes in temperature over diurnal and seasonal timescales. The analysed data was temperature-corrected using the temperature readings from three co-located temperature sensors. Thus, the strain measurements still show a strong correlation with temperature. The strain readings cannot be accurately differentiated between the temperature change and the opening and closing of the concrete joints. It is also necessary to mention that we could not identify the dynamic signal of passing earthquake waves in the static strain data. The lack of these signals being identified in the strain recordings could be due to the low sampling frequency of $1 \mathrm{~Hz}$ employed by these sensors, and thus the passage of seismic waves might be detected by a higher frequency of sampling by the stain meters (e.g., several tens or hundreds of Hz). Further studies should take this into account.

\section{Conclusions}

The monitoring of existing dams by seismic sensors has the potential to allow an evaluation of their dynamic characteristics in terms of their response to ground-shaking-induced loading. These characteristics can be utilized as management indices to reveal any anomalies or degradation by detecting deviations in the resonant frequencies. Within this context, it is essential to accumulate and analyse data in relation to all aspects of the dam's operations and its structural behaviour in response to such loadings, as well as the impact of seasonal temperature variations. These analyses will need to be undertaken periodically or continuously (preferably), especially following major events, e.g., seismic events or extremes in temperature. This would allow temporal (long-term) changes in the fundamental frequencies to be identified, including that associated with ageing. For example, the analysis of the fundamental frequency following the example event studied here showed a rapid recovery to the pre-event value, but a similar analysis (preferably in real-time which is possible with the seismic sensors used) would need to be done following larger events.

Analysis of the acquired data will be continued, in particular, on how the dam's structural parameters (i.e., the relevant fundamental frequencies of vibration) vary with temperature, and how it responds in more detail to the number of generators in operation, as well as when excess water is being funnelled through the side spillway. Complementarily, absolute static displacements due to seasonal effects or longterm degradation effects could be measured by GPS sensors placed on top of each segment that makes up the dam's structure.

Future research in such activities will need to consider the minimum numbers of different measurement units and their spatial distribution to be installed. For example, seismic sensing units should be installed at the base of the dam to determine the seismic loading that will shake the dam (e.g., Pagano $\&$ Sica, 2013), or in the tunnels where the strain and temperature meters were located, as well as on each of the 13 structural blocks. However, here the communications problems that had arisen would need to be resolved. Furthermore, additional work is required to improve the sensors themselves to make them more robust given the changeable weather conditions, and to ensure the more stable dissemination of the acquired data via the internet. Considering the strain sensors, as discussed above, a higher sampling rate (of the order of several hundred $\mathrm{Hz}$ ) would be required to better identify the relative movement of the blocks making up the dam during seismic events. 


\section{Acknowledgements}

The MI-DAM project benefited from support from the German Ministry for Education and Research (contract 03G0877). The project acknowledges the valuable support and assistance provided by the management and staff of the Kurpsai Hydroelectric Power Station, and the Ministry of Emergency Situations of the Kyrgyz Republic for permitting us to conduct this study. The analysis and figures in this work were undertaken using Matlab, Generic Mapping Tools (Wessel et al., 2013), and Pyrocko (Heimann et al., 2017).

\section{Funding}

Open Access funding enabled and organized by Projekt DEAL. The MI-DAM project is supported by the German Ministry for Education and Research (contract 03G0877).

\section{Data Availability}

Data described and analysed in this manuscript were collected by GFZ Potsdam. Data will be made available upon request. Data of the Central Asia Strong Motion Network ACROSS are available through GEOFON through the European waveform Data Archive (EIDA).

\section{Code Availability}

Codes can be made available upon request.

\section{Declarations}

Conflict of Interest The authors declare that the research was conducted in the absence of any commercial or financial relationships that could be construed as a potential conflict of interest.

Open Access This article is licensed under a Creative Commons Attribution 4.0 International License, which permits use, sharing, adaptation, distribution and reproduction in any medium or format, as long as you give appropriate credit to the original author(s) and the source, provide a link to the Creative Commons licence, and indicate if changes were made. The images or other third party material in this article are included in the article's Creative Commons licence, unless indicated otherwise in a credit line to the material. If material is not included in the article's Creative Commons licence and your intended use is not permitted by statutory regulation or exceeds the permitted use, you will need to obtain permission directly from the copyright holder. To view a copy of this licence, visit http://creativecommons.org/licenses/by/4.0/.

Publisher's Note Springer Nature remains neutral with regard to jurisdictional claims in published maps and institutional affiliations.

\section{REFERENCES}

Abrahamson, N. A. (2005). Effect of local site condition on spatial coherency. Electric Power Research Institute, Rpt. No. RP297805 .

Abrahamson, N. A., Schneider, J. F., \& Stepp, J. C. (1991). Empirical spatial coherency functions for application to soilstructure interaction analyses. Earthquake Spectra, 7(1), 1-27.

Astorga, A., Guéguen, P., \& Kashima, T. (2018). Nonlinear elasticity observed in buildings during a long sequence of earthquakes. Bulletin of the Seismological Society of America, 108(3A), 1185-1198.

Astorga, A., Guéguen, P., Rivière, J., Kashima, T., \& Johnson, P. A. (2019). Recovery of the resonance frequency of buildings following strong seismic deformation as a proxy for structural health. Structural Health Monitoring, 18(5-6), 1966-1981.

Astorga, A., \& Guéguen, P. (2020). Influence of seismic strain rates on the co-and post-seismic response of civil engineering buildings. Earthquake Engineering \& Structural Dynamics, 49(15), 1758-1764.

Auger, F., \& Flandrin, P. (1995). Improving the readability of timefrequency and time-scale representations by the reassignment method. IEEE Transactions on Signal Processing, 43(5), 1068-1089.

Bi, K., \& Hao, H. (2009). Analysis of influences of an irregular site with uncertain soil properties on spatial seismic ground motion coherency. In AEES 2009 Conference. Newcastle Australia.

Boxberger, T., Fleming, K., Pittore, M., Parolai, S., Pilz, M., \& Mikulla, S. (2017). The Multi-Parameter Wireless Sensing System (MPwise): Its description and application to earthquake risk mitigation. Sensors, 17, 2400.

Cooley, J, and Tukey, J (1965) An algorithm for machine calculation of complex Fourier series. Mathematics of computing, reprinted 1972. Digital signal processing. IEEE Press, pp. 223-227.

Fleming, K., Picozzi, M., Milkereit, C., Kühnlenz, F., Lichtblau, B., Fischer, J., Zulfikar, C., Özel, O., \& the SAFER and EDIM working groups. (2009). The Self-Organizing Seismic Early Warning Information Network (SOSEWIN). Seismological Research Letters, 80(5), 755-771. https://doi.org/10.1785/gssrl. 80.5.755

Grunwald, S. (2012). Central Asia regional economic cooperation: Power sector regional master plan, Asian Development Bank, 
Technical assistance consultant's report, 43549, Stuttgart, Germany.

Havenith, H. B., Strom, A., Torgoev, I., Torgoev, A., Lamair, L., Ischuk, A., \& Abdrakhmatov, K. (2015a). Tien Shan geohazards database: Earthquakes and landslides. Geomorphology, 249, 16-31. https://doi.org/10.1016/j.geomorph.2015.01.037

Havenith, H. B., Torgoev, I., Torgoev, A., Strom, A., Lamair, L., Xu, Y., \& Fernandez-Steeger, T. (2015b). The Kambarata 2 blast-fill dam, Kyrgyz Republic: Blast effect, geophysical monitoring and dam structure monitoring. Geoenvironmental Disaster, 2, 11. https://doi.org/10.1186/s40677-015-0021-X

Havenith, H.-B., Torgoev, A., Braun, A., Schlögel, R., \& Micu, M. (2016). A new classification of earthquake-induced landslide event sizes based on seismotectonic, topographic, climatic, and geologic factors. Geoenvironmental Disasters. https://doi.org/10. 1186/s40677-016-0041-1

Heimann, S., Kriegerowski, M., Isken, M., Cesca, S., Daout, S., Grigoli, F., Juretzek, C., Megies, T., Nooshiri, N., Steinberg, A., Sudhaus, H., Vasyura-Bathke, H., Willey, T., \& Dahm, T. (2017). Pyrocko-An open-source seismology toolbox and library. V. 0.3. GFZ Data Services. http://doi.org/https://doi.org/ 10.5880/GFZ.2.1.2017.001

International Hydropower Association (2018) 2018 Hydropower status report, London, UK.

International Seismological Centre (2020), On-line Bulletin, https://doi.org/10.31905/D808B830, Last Accessed 20 July 2020.

Ischuk, A., Bjerrum, L. W., Kamchybekov, M., Abdrakhmatov, K., \& Lindholm, C. (2017). Probabilistic Seismic Hazard Assessment for the area of Kyrgyzstan, Tajikistan, and Eastern Uzbekistan, Central Asia. Bulletin of the Seismological Society of America, 108(1), 130-144. https://doi.org/10.1785/012016033

Johnson, P. A., \& Jia, X. (2005). Nonlinear dynamics, granular media and dynamic earthquake triggering. Nature, 437(7060), 871-874.

Kalmetieva, Z. A., Mikolaichuk, A. V., Moldobekov, B. D., Meleshko, A. V., Jantaev, M. M., \& Zubovich, A.V. (2009). Atlas of earthquakes in Kyrgyzstan (editor in chief of the English version: H.B. Havenith), Central Asian Institute of Applied Geosciences, Bishkek, Kyrgyz Republic, p. 75.

Kita, A., Cavalagli, N., \& Ubertini, F. (2019). Temperature effects on static and dynamic behavior of Consoli Palace in Gubbio, Italy. Mechanical Systems and Signal Processing, 120, 180-202.

Kormev, Y. P. (1981). Kurpsai hydroelectric station on the Naryn River. Hydrotechnical Construction, 15(11), 652-659.

Koufoudi, E., Chaljub, E., Douste-Bacqué, I., Roussel, S., Bard, P.Y., Larose, E., Dufour, F., Humbert, N., \& Baillet, L. (2018). A high-resolution seismological experiment to evaluate and monitor the seismic response of the Saint-Guérin Arch Dam, French Alps. Seismological Research Letters, 89(4), 1576-1582.

McNamara, D. E., \& Buland, R. P. (2004). Ambient noise levels in the continental United States. Bulletin of the Seismological Society of America, 94(4), 1517-1527.

Michel, C., \& Guéguen, P. (2010). Time-frequency analysis of small frequency variations in civil engineering structures under weak and strong motions using a reassignment method. Structural Health Monitoring, 9(2), 159-171.
Nadim, F., Kjekstad, O., Peduzzi, P., Herold, C., \& Jaedicke, C. (2006). Global landslide and avalanche hotspots. Landslides, 3, 159-173. https://doi.org/10.1007/s10346-006-0036-1

Pagano, L., \& Sica, S. (2013). Earthquake early warning for earth dams: Concepts and objectives. Natural Hazards, 66, 303-318. https://doi.org/10.1007/s11069-012-0486-9

Parolai, S., Boxberger, T., Pilz, M., Fleming, K., Haas, M., Pittore, M., Petrovic, B., Moldobekov, B., Zubovich, A., \& Lauterjung, J. (2017). Assessing earthquake early warning using sparse networks in developing countries: Case study of the Kyrgyz Republic. Frontiers in Earth Science, 5, 74. https://doi.org/10. 3389/feart.2017.00074

Pereira, S., Magalhaes, F., Gomens, J. P., Cunha, A., \& Lemos, J. V. (2018). Dynamic monitoring of a concrete arch dam during the first filling of the reservoir. Engineering Structures, 174, 548-560. https://doi.org/10.1016/j.engstruct.2018.07.076

Petryna, Y., Kähler, P. and Elsesser, W. (2019) Long-term SHM system for a concrete dam, Proceedings of the 5th Conference on Smart Monitoring Assessment and Rehabilitation of Civil Structures, SMAR 2019, Potsdam, DGFZfP.

Picozzi, M., Parolai, S., Mucciarelli, M., Milkereit, C., Bindi, D., Diommaso, R., Vona, M., Gallipoli, M. R., \& Zschau, J. (2011). Interferometric analysis of strong ground motion for structural health monitoring: The example of the L'Aquila, Italy, Seismic Sequence of 2009. Bulletin of the Seismological Society of America, 101(2), 635-651. https://doi.org/10.1785/0120100070

Picozzi, M. (2012). An attempt of real-time structural response assessment by an interferometric approach: A tailor-made earthquake early warning for buildings. Soil Dynamics and Earthquake Engineering, 38, 109-118. https://doi.org/10.1016/j. soildyn.2012.02.003

Pilz, M., Fleming, K., Boxberger, T., Orunbaev, S. (2019) Structural health monitoring of the Kurpsai dam in the Kyrgyz Republic, Proceedings of the 5th Conference on Smart Monitoring Assessment and Rehabilitation of Civil Structures, SMAR 2019, Potsdam, DGFZfP.

Thompson, S. C., Weldon, R. J., Rubin, C. M., Abdrakhmatov, K., Molnar, P., \& Berger, G. W. (2002). Late Quaternary slip rates across the central Tien Shan, Kyrgyzstan, central Asia. Journal of Geophysical Research. https://doi.org/10.1029/2001JB000596

Wessel, P., Smith, W. H. F., Scharroo, R., Luis, J., \& Wobbe, F. (2013). Generic mapping tools: Improved version released. Eos, Transactions of the American Geophysical Union, 94(45), 409-410. https://doi.org/10.1002/2013EO450001

Xu, Y., Roecker, S. W., Wei, R., Zhange, W., \& Wei, B. (2006). Analysis of seismic activity in the crust from earthquake relocation in the Central Tien Shan. Bulletin of the Seismological Society of America, 96(2), 737-744. https://doi.org/10.1785/ 0120030220

Zerva, A., \& Harada, T. (1997). Effect of surface layer stochasticity on seismic ground motion coherence and strain estimates. Soil Dynamics and Earthquake Engineering, 16(7-8), 445-457.

Zerva, A. (1999) Spatial variability of seismic ground motions: stochastic techniques and physical patterns. In Earthquake Engineering-Invited Papers: Proceedings of the eleventh European conference, Paris, France, 6-11 September 1998 (Vol. 2, p. 199). CRC Press. 